\title{
THE EFFECT OF MULTIMEDIA USE ON THE TEACHING AND LEARNING OF SOCIAL SCIENCES AT TERTIARY LEVEL: A CASE STUDY
}

\author{
DOI: http://dx.doi.org/10.17159/2223-0386/2017/n17a1 \\ Luiza de Sousa \\ Faculty of Education Sciences \\ North-West University, Potchefstroom Campus \\ luiza.desousa@nwu.ac.za
}

Barry Richter

Faculty of Education Sciences

North-West University

Potchefstroom Campus

barry.richter@nwu.ac.za

\author{
Carisma Nel \\ Faculty of Education Sciences \\ North-West University \\ Potchefstroom Campus \\ carisma.nel@nwu.ac.za
}

\section{Abstract}

Instructors in higher education are under pressure to provide their students with more effective and efficient learning environments and educational experiences. Instructional systems and educational technology have been receiving great attention from educators in order to enhance students' learning. Educational technologies such as multimedia presentations are becoming commonplace. The aim of the research reported in this article was to establish which multimedia combinations are best for the teaching and learning of Social Sciences content. A quasi-experimental research design was used to establish how exposure to different multimedia combinations on digital videodisc may affect the achievement of pre-service teachers. The results of the study indicate that when using various multimedia combinations, the unique nature of Social Sciences can be addressed effectively.

Keywords: History Education; Geography education multimedia; Social Sciences education; Teaching and learning; Tertiary/higher education; Educational technology integration.

\section{Introduction}

A medium is "an intervening agency, means, or instrument by which something is conveyed or accomplished" (Webster's College Dictionary, 1991). The plural form of medium is media, which, in the context of education, includes the means to create, store and present instructional content. These include tools such as chalk and talk, books and computers, slide projectors, video projection, overhead projectors, document cameras, audio systems (a 
CD player, radio), combined sound and video systems (television, digital video cameras, and DVDs), and the media objects themselves. The term multimedia was introduced in the 1960s to describe the combined use of several media, such as text, film, video, still images, and audio (Vincent \& Shepherd, 1989). Schnotz and Lowe (2003) define the term multimedia as the combination of multiple technical resources for the purpose of presenting information represented in multiple formats via multiple sensory modalities.

In the late 1990s a number of surveys and reports in the United States highlighted the role of teacher education in preparing new teachers to use technology in the classroom (National Council for Accreditation of Teacher Education, 1997; Persichitte et al., 1998; Jacobsen et al., 2003). The general finding was that although technology use is increasing in teacher training programmes, teacher educators could do more to help pre-service teachers learn to integrate educational technology into their teaching and learning (Zeng et al., 2016:2; Bridges.org, 2002). Multimedia allows lecturers to integrate text, graphics, animation, and other media into one package to present comprehensive information for their students to achieve specified course outcomes. It permits the demonstration of complicated processes in a highly interactive, animated fashion and that instructional material can be interconnected with other related topics in a more natural and intuitive way (Crosby \& Stelovsky, 1995). Jarosievitz (2011:22; 2009:383) encourages university lecturers to take advantage of multimedia (text, pictures, animation, sound, video and interactivity) and new devices and their applications so as to ensure that pre-service teachers leave university with adequate knowledge and applicable skills.

Multimedia-based instruction can be efficient and effective for three reasons (Issa, Cox \& Killingsworth, 1999):

- $\quad$ it is self-paced learning: the individualized pace of the learning allows students to break down the group instructional setting, which often inhibits some people's natural progression (West \& Crook, 1992);

- it includes video/audio production, enhancing a learner's interaction with the course material through less bridging effort between the learner and the information being processed, and

- it provides autonomy in the learning process: self-regulated instruction shifts the sense of responsibility from the instructor to the student.

Bartlett and Strough (2003) state that, besides potential advantages to students, multimedia formats may offer benefits to instructors teaching multi- 
section courses because this type of format ensures uniformity in the lecture content across the sections.

The media mentioned above targets either the eye or the ear. Of the five human senses, vision is recognized as the most powerful data-acquisition device for the brain. Tufte (1990:31), a professor of statistics and graphic design at Yale University, explains why the most effective presentation methodologies attempt to convey information visually, rather than verbally alone. "Visual displays of information encourage a diversity of individual viewer styles and rates of editing, personalizing, reasoning, and understanding. Unlike speech, visual displays are simultaneously a wideband and a perceiver-controllable channel”.

The terms "wideband" and "channel" come from the science of communications. The term channel in this context is the same as medium, pathway or route, along which data travel. A wideband channel carries more data at higher speeds. A visual display is an example of a wideband channel that carries more data at higher speeds than simple speech. A visual display is also "perceiver controllable" in that the person doing the viewing can absorb the data by scanning them at a speed and in a sequence that most naturally fits that person's intellectual strengths. Gardner (1999:30), in keeping with his theory of multiple intelligences, would agree that each individual assimilates knowledge differently, depending on the make-up of his or her mind. Speech, on the other hand, though it is a powerful medium for communication when used by skilled speakers, is not so easy to digest. It requires more mental effort to assimilate because less information is conveyed at a slower speed, thus requiring more concentration and extrapolation on the part of the listener.

Students who are given access to multimedia courseware, whether as individuals or in groups, can take control of their own learning, constructing knowledge at a pace and in a direction that suits their needs and desires. Otts, Williams, Dawson and Alley (2004) express this idea in compelling terms when they state: "The MTV generation quickly loses interest in maths topics presented on the chalkboard by some old fuddy-duddy 60s fossil lecturing about polynomials and rational numbers. A step forward is the use of the overhead projector, but students require even greater stimuli to hold their attention. Use of multimedia brings teaching methods into the 21st century and helps students catch the dream of success in the 90s and beyond". Multimedia offers avenues for presenting material not possible with other methods, such as: 
- interaction;

- $\quad$ animation to demonstrate concepts;

- $\quad$ sound cues;

- incorporation of stimulating visual effects such as flashing, and

- nonlinear progression.

New capabilities allow teacher-made [presentations] to be accessed via the internet, allowing students the opportunity to study at home. The constructivist approach to learning in which the learner plays an active role in the teaching and learning process can further encourage students to learn through personal experiences with suitable learning material and teachers should use new and effective modes, ways, and designing thoughts into multimedia teaching practice (Shah \& Khan, 2015:357; Gilakjani, 2012:60). The inclusion of onscreen information sources proposes opposite reactions to printed text that may contribute critical and objective skills development, since studies have shown the effectiveness of multimedia over traditional lecture methods (Shah $\&$ Khan, 2015:350; Lee, 2002:513-514). Visual multimedia explanations may help to distinguish between primary and secondary sources, especially when application of knowledge is required to answer questions (Van Eeden, 1999). However, one must remember that the unique characteristics of a subject influence the success of learning via picture or audio presentations (Nugent, 1982:164). Similarly, if concepts are too difficult to understand, presentations will not be successful, no matter what the combination of media (ChanLin, 1998:1).

The Department of Basic Education (DBE) (DoE, 2003:13) states that "The present situation ... cannot be maintained if South Africa is to address the digital divide. Like most parts of the world, the South African education and training system has to respond to the pressures and challenges posed by the information revolution". Currently, the DBE's Schooling 2030 goals strive to expand to a wide range of media, amongst learners, so as to enrich their education. It refers to e-Education as one of two key areas of innovation for the basic education sector since Information and Communication Technology (ICT) has the potential to improve and diversify learning (DBE, 2015:3, 16).

In the training of teachers in South Africa it is therefore necessary for aspirant teachers to get enough exposure to the incorporation of educational technology into the subjects offered in the General Education and Training (GET) Band (Evoh, 2007:84). Social Sciences (SS) is a compulsory subject in the GET Band (Grades 4-9) in South African schools. The National Curriculum Statement, the policy document of the DBE and the National Curriculum 
and Assessment Policy Statement (CAPS) for SS in both the Intermediate and Senior phases state that History and Geography are two disciplines that must be kept separate, but both must complement the knowledge (content, skills and concepts) outlined in the official documentation (DBE, 2011a:8; DBE, 2011b:8). The research reported in this article makes known which forms of multimedia combinations are best for the teaching and learning of SS content in specific study themes offered in SS. In this research multimedia was incorporated into the SS subject offered in the training of teachers for the Intermediate Phase (i.e. Grades 4-6).

Jarosievitz (2011:22, 2009:383) encourages university lecturers to take advantage of the ICT, multimedia (text, pictures, animation, sound, video and interactivity), and new devices and their applications so as to ensure that pre-service teachers leave university with adequate knowledge and applicable skills. Research using the "flip the classroom" method has shown advantages in that students became more active and motivated to read, and to watch the video given in the e-learning material. They felt they were better prepared and more active learners during the lectures, not only passive listeners. Students used tablets or smart phones as learning devices in a project plan based on constructivism. The stages of the project were defined with the aim to create e-learning content for students in a BSc course. The disadvantages of this method are that more preparation work is required from the lecturer (Jarosievitz, 2015:2,5). Multimedia as a technology-based constructivist learning environment enables students to solve problems by means of selfexploration, collaboration and active participation. Simulations, models and media-rich study materials (still and animated graphics, video and audio) integrated in a structured manner can facilitate the learning of new knowledge. Multimedia learning encourages and enhances peer learning, individual creativity and innovation (Malik \& Agarwal, 2012:468).

\section{Conceptual and theoretical framework}

In general, ICT and multimedia have been used in education for more than 25 years (Rodriguez, Nussbaum, López \& Sepúlveda, 2010:166). In teacherdriven education, multimedia lessons were found to be effective in teaching road signs and speed limits and produced higher levels of performance than non-multimedia instruction (Lee \& Keckley, 2006). This highlights that the unique characteristics of a subject influence the success of learning via picture or audio presentations (Nugent, 1982:164). 
In the past 20 years of teaching History in schools, ICT with multimedia (e.g. text, images and audio) have been used regularly to support teaching and learning (Weiner, 1995; Van Eeden, 1999; Munro, 2000). History lessons have become more active and learner-centred with respect to ICT integration and the use of multimedia resources in teaching and learning at schools in South Africa. In fact, researchers of History teaching recommend the use of a wide variety of multimedia resource material (text, images and audio) (De Sousa \& Van Eeden, 2009:18). In SS the representation of information by using the visualization capabilities of video are said to be immediate and powerful. In History lessons, multimodal information through images and animations, pictures, including sound and speech are recommended for deep understanding. For example, when illustrating a war, replicas of war equipment can be prepared and geographical locations can be illustrated. Such videos consist of a high degree of reality and visualization. Geography lessons also make use of many maps, animations and videos. Animations, when combined with user input, enable students to view different versions of change over time, depending on different variables. Graphics provide creative possibilities for a learning experience (Ekinci, Karakoç, Hut \& Avc1, 2009:95, $96,99)$. The reasons why multimedia is promoted in SS education are that it is readily available for use, helps make remembering easy, and more information can be shared faster and in an interesting format (Ekinci et al., 2009:12).

Multimedia has succeeded in psychomotor development and strengthening of visual processing of the intended users in multi-disciplinary multimedia educational programmes where DVDs were also used as multimedia technology (Malik \& Agarwal, 2012:470). The integration of ICT and multimedia into SS by means of a portable DVD player may be used as the foundation for a mind-shift that must be made at universities to teach SS. The mind-shift involves the integration of ICT not only to learn a specific skill, but also to integrate multimedia resources into the teaching and learning of pre-service teachers, who can then apply their experience to teaching in schools. The inclusion of on-screen information sources proposes opposite reactions to traditional historical printed text and contributes to the development of critical and objective skills development (Lee, 2002:513-514). Visual multimedia explanations may help to distinguish between primary and secondary sources, especially when application of knowledge is required to answer questions (Van Eeden, 1999). 
Geography is a highly visual subject and is complemented with the use of multimedia resources (Peterson, 1994:27). Audio-visual resources have been used effectively at tertiary institutions to support teaching and learning in Geography. Visual presentations and representation are integral parts of Geography education (e.g. imported digital images, PowerPoint presentations, satellite images via the World Wide Web, etc.) (McKendrick \& Bowden, 1999). However, one should be cautious to not only rely on multimedia without text, since research has also revealed that text is more advantageous as the material becomes more complex. This highlights the important advantage of text for the presentation of complex materials (Nugent, 1982:164).

Students will be successful in their learning task if they interact meaningfully with their academic material, select relevant verbal and non-verbal information, organise information into corresponding mental models, and integrate new representations with existing knowledge when learning with multimedia (Mayer, 2002:60). An important aspect required for multimedia learning is that learners must be able to hold corresponding visual and verbal representations in short-term memory simultaneously.

Based on Mayer's assumptions and research, the cognitive theory related to multimedia learning has shown how people construct knowledge from words and pictures (Mayer \& Moreno, 2003:50). Research has revealed that deeper learning is achieved when the following multimedia combinations are used: text and picture explanations rather than verbal explanations; exclusion of irrelevant words, sounds and video; avoidance of complex verbal and pictorial representations with no guidance for low-prior knowledge learners; and words presented in a personalised conversational style, rather than a detailed description style (Mayer, 2001:44; Mayer, 2002:62-67; Moreno, 2004:102).

In the implementation of multimedia it is accepted that the human mind is a two-channel system of information processing with limited capacity. It has visual/pictorial and verbal/auditory processing channels (Mayer, 2003:136). Once the human mind receives information for cognitive processing, it selects, organises and integrates the mental representations promoting meaningful learning (See Image 1). The cognitive processing by the learner is believed to cause learning and not the media environment (Mayer, 2003:137). 
Image 1: The cognitive theory of multimedia learning

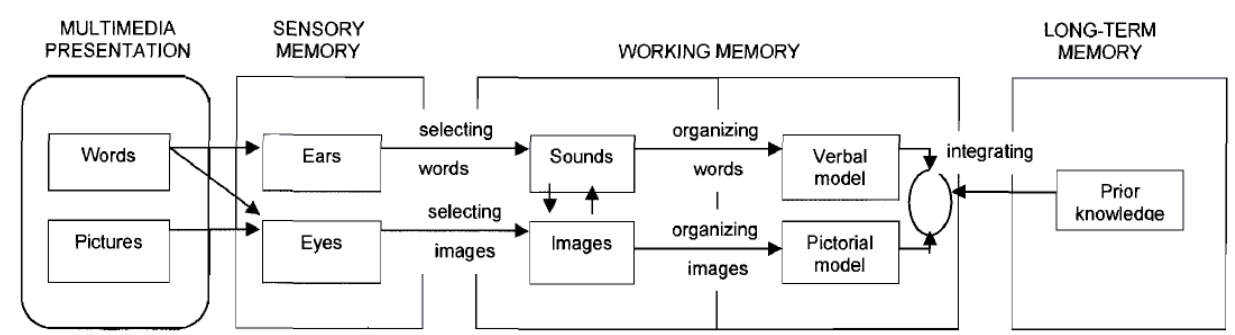

Source: Mayer, 2001:44.

Image 1 represents the cognitive model of multimedia learning of the human information processing system. The boxes represent memory stores, being sensory, short-term and long-term memory (Mayer, 2001). Pictures and words as a multimedia presentation enter the sensory memory through the eyes and ears. The sensory memory allows pictures to be registered in the eyes and held as visual images in a visual sensory memory for a short span of time. Text (printed words) is processed in the visual channel and then moves to the auditory channel. Spoken words and sound are registered in the ears and held as auditory images in the auditory sensory memory for a brief period. The core of multimedia learning takes place in the short-term memory where knowledge is held temporarily. Short-term memory is divided into two sections based on the two sensory modalities, namely visual and auditory. The left side of Image 1 represents raw material in the form of sound (words) and images (pictures), with an arrow from sounds to images representing the mental conversion of a sound into a visual image. The arrow from images to sounds represents the mental conversion of a visual image into a sound image. The right side of Image 1 represents knowledge construction of visual and verbal mental models and the link between the two (Mayer, 2001). The arrows labelled selecting (moving from the presented material to short-term memory), organising (moving from one kind of representation in short-term memory to another), and integrating (moving information from long-term memory to shortterm memory and between visual and auditory representation in short-term memory) represent the main cognitive processes needed for multimedia learning. The last box is labelled long-term memory. The arrow from long-term memory to short-term memory represents the knowledge that a person has acquired that must actively be brought to short-term memory so that one can actively think about this material in long-term memory (Mayer, 2001). During the cognitive process of integrating, the learner mentally connects the verbal and pictorial models as well as the applicable prior knowledge from the long-term memory (Mayer, 2002:60). 
The following empirical investigation was based on the insights flowing from the conceptual and theoretical framework.

\section{Empirical investigation}

The total population $(n=315)$ of first-year education students at the participating university taking the compulsory module in SS was chosen to participate in the research. A quasi-experimental research design (Leedy \& Ormrod, 2005) was used. Four groups ( \pm 80 students in a group) were exposed to different experimental interventions and the groups acted as their own controls. The measuring instruments included short tests during classes, a semester test and a final examination All the tests comprised multiplechoice questions. The examination required multiple-choice responses as well as written answers. The mastering of knowledge on the correct cognitive skill and level (NQF level 5 for first-year students) was chosen in compliance with the guidelines formulated in the university moderator's report.

Each group acted as the control group and the experimental group twice, due to the nature of the subject. Each SS student received two multimedia DVDs, one for History and one for Geography, together with a portable DVD player when part of the experimental group. The results of the control group and each experimental group were compared.

The two DVDs contained different multimedia, ensuring that the research was rooted in the cognitive theory of multimedia learning's dual channel system of information processing (Gilakjani, 2012:58,59). One contained predominantly text with audio recordings (DVD 1) and the other contained still graphics, audio recordings, text and video clips (DVD 2).

The introduction of DVD 1 in History featured the lecturer against a historical backdrop. For the theme dealing with sources, the introduction's setting was a local museum. The motivation for this was to create the context for and to enliven the theme. The text screens introduced the theme and the module outcomes. Both History themes, the first dealing with Sources and the second with Democracy, contained verbal explanations presented by the lecturer as well as text accompanied by audio recordings. Geography's DVD 1 featured the lecturer in front of a geographical backdrop. Screens containing text introduced the theme and the module outcomes, which focused specifically on knowledge and application aspects. For Geography, the themes Natural Resources and Sustainable Development contained verbal explanations and on-screen text accompanied by audio recordings. The 
Natural Resources theme featured a text statement with an answer once the correct option (True or False) had been chosen.

History's DVD 2 with Sources as theme was filmed in a museum so that first-hand primary sources could be viewed. In both History themes (Sources and Democracy) text focusing on knowledge and application was used. Explanations accompanied by audio recordings also featured. Still images were included to enable visualisation of the theme as the explanation was given. Many structured mind maps were shown on screen, setting out the theory chronologically and orderly for the Democracy theme. Permission was obtained from a television channel and a council to show excerpts from their programmes, providing clips of current affairs associated with the themes Sources and Democracy. Independent video clips from television were also used for these themes.

Geography's DVD 2 for the themes Natural Resources and Sustainable Development featured the lecturer against a geographical background. Text screens introduced the theme and outcomes. Explanations by the lecturer as well as text were accompanied by audio recordings. Still and moving images and maps were also used to ensure visualisation of the themes while the explanations were given. A statement featured on the disc, as text, with an answer also given as text once the correct option (True or False) was chosen was used as self-assessment. There were also video clips of current affairs associated with the theme.

The data collected after each assessment opportunity and its analysis were centred on the assessment of the two outcome levels, namely knowledge and application for History and Geography respectively when using different multimedia DVDs.

\section{The analysis of data}

The Analysis of Covariance Design (ANCOVA) was used to analyse the data and to test if the means of the populations differed from one another (Leedy \& Ormrod, 2005) among the four groups that were not equal in size. ANCOVA was used to analyse the data because it "looks for differences among three or more means", controlling for the influence of another continuous variable (in this case the post-test mark was "adjusted" for variability on the covariate/ pre-test (Leedy et al., 2005:274). This was done to test if the means of the populations differed from one another. In this way, it compared the variances $\left(s^{2}\right)$ within and also across the groups, controlling for the covariate. 
Statistical significance (p-values) as well as practical significance (d-values) are reported in the discussion of results of the analysed data (Ellis \& Steyn, 2003). The effect size is a measure of practical significance, using Cohen's $\mathrm{d}$-value and was calculated using the formula:

$$
d=\frac{\left|\bar{x}_{i}-\bar{x}_{j}\right|}{\sqrt{M S E}}
$$

where $\left|\bar{x}_{1}-\bar{x}_{2}\right|$ is the difference between $\bar{x}_{1}$ and $\bar{x}_{2}$ without taking the sign into consideration and MSE the mean square error of the ANCOVA.

Guidelines for interpretation are (a) small effect: $d=0.2$, (b) medium effect: $\mathrm{d}=0.5$ and (c) large effect: $\mathrm{d}=0.8$ ' (Ellis et al., 2003:52-53). For each comparison of the control group with each experimental group's intervention, knowledge and application outcomes were assessed for History and Geography respectively.

\section{Results}

Table 1 shows the mean scores of SS pre-test results, where all four groups performed fairly the same with means ranging from $15 \%-16.8 \%$, yielding no statistical significance and no practical significance among the groups, as all the effect sizes were small and not practically significant. Therefore, all four groups were presumed to be comparable.

Table 1: Pre-test means, pre-test standard deviations and p-value for groups C, D, E \& F

\begin{tabular}{|l|l|l|l|l|}
\hline Group & C & D & E & F \\
\hline Pre-test Mean \% & 16.5 & 15.0 & 16.8 & 15.2 \\
\hline Pre-test Standard Deviation & 4.7 & 5.2 & 5.1 & 4.6 \\
\hline p-value 0.0664 & & & & \\
\hline
\end{tabular}

\section{History analysis and results for the theme Sources}

The analysis of Table 2 below shows the adjusted mean scores, mean square errors, p-values and the effect sizes (d-values) of ANCOVA for Test 1 and the Semester Test. The table refers to Knowledge and Application questions answered in the History theme sources, adjusted for the pre-test results.

With regard to the attainment of Application outcomes in Test 1, the results indicated that statistically the groups differed significantly (p-value 0.0253). 
The control group (E and $\mathrm{F}$ ), who received a traditional lecture, performed visibly better $(\mathrm{d}=0.4)$ by more than $10 \%$ ( $c f$. Tables 2$)$.

Table 2: Adjusted mean scores, mean square errors, p-values and effect sizes (d-values) of ANCOVA for the theme Sources

\begin{tabular}{|c|c|c|c|c|c|c|c|c|c|}
\hline \multirow{2}{*}{\multicolumn{2}{|c|}{$\begin{array}{l}\text { History Theme } \\
\text { Sources }\end{array}$}} & $\begin{array}{c}\text { Control } \\
\text { group } \\
(\mathrm{E} \& \mathrm{~F})\end{array}$ & $\begin{array}{c}\text { Group C } \\
\text { (Multimedia- } \\
\text { DVD 2) }\end{array}$ & $\begin{array}{c}\text { Group D } \\
\text { (Text-DVD 1) }\end{array}$ & \multirow{3}{*}{\begin{tabular}{|c|c}
$\begin{array}{c}\text { Mean Square } \\
\text { Error }\end{array}$ \\
643.4 \\
\end{tabular}} & \multirow{3}{*}{$\begin{array}{c}\text { p-value } \\
0.6006\end{array}$} & $\begin{array}{c}\text { Group C } \\
\text { (Multimedia) } \\
\& \\
\text { Control group } \\
\text { (E \& F) } \\
\end{array}$ & $\begin{array}{c}\text { Group D } \\
\text { (Text) } \\
\& \\
\text { Control group } \\
\text { (E \& F) }\end{array}$ & $\begin{array}{c}\text { Group C } \\
\text { (Multimedia) } \\
\& \\
\text { Group D } \\
\text { (Text) }\end{array}$ \\
\hline & & \multicolumn{3}{|c|}{$\begin{array}{l}\text { Adjusted Mean } \\
\%\end{array}$} & & & \multicolumn{3}{|c|}{ d-value } \\
\hline \multirow{2}{*}{$\overrightarrow{5}$} & Knowledge & 52.5 & 55 & 50.7 & & & 0.1 & 0.1 & 0.2 \\
\hline & Application & 51.1 & 40.8 & 41.7 & 583.4 & 0.0253 & 0.4 & 0.4 & 0.0 \\
\hline \multirow{2}{*}{ 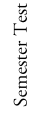 } & Knowledge & 63 & 58.6 & 54.1 & 624.4 & 0.0593 & 0.2 & 0.4 & 0.2 \\
\hline & Application & 67.3 & 70.1 & 70.3 & 505.28 & 0.5508 & 0.1 & 0.1 & 0.0 \\
\hline
\end{tabular}

\section{History analysis and results for the theme Democracy}

The analysis of Table 3 below shows the adjusted mean scores, mean square errors, p-values and the effect sizes (d-values) of ANCOVA for Test 2 and the examination. The table refers to Knowledge and Application questions answered in the History theme Democracy, adjusted for the pre-test results.

The mean scores of the three groups who answered Application outcome in the examination differed significantly statistically. The mean score of group E $(62.3 \%)$, who received the still and moving graphics, documentary excerpts, etc., was the highest and was visibly better than group $\mathrm{F}$ ( $c f$. Table 3 ).

Table 3: Adjusted mean scores, mean square errors, p-values and effect sizes (d-values) of ANCOVA for the theme Democracy

\begin{tabular}{|c|c|c|c|c|c|c|c|c|c|}
\hline \multirow{2}{*}{\multicolumn{2}{|c|}{$\begin{array}{c} \\
\text { History Theme } \\
\text { Democracy }\end{array}$}} & \multirow{2}{*}{\multicolumn{2}{|c|}{\begin{tabular}{c|c}
$\begin{array}{c}\text { Control } \\
\text { group } \\
(\mathrm{C} \& \mathrm{D})\end{array}$ & $\begin{array}{c}\text { Group E } \\
\text { (Multimedia) }\end{array}$ \\
& \\
& Adjusted Mean \\
$\%$
\end{tabular}}} & \multirow[t]{2}{*}{$\begin{array}{c}\text { Group F } \\
\text { (Text) }\end{array}$} & & & \multirow[t]{2}{*}{$\begin{array}{c}\text { Group E } \\
\text { (Multimedia) } \\
\& \\
\text { Control group } \\
\text { (C \& D) }\end{array}$} & \multirow{2}{*}{$\begin{array}{c}\begin{array}{c}\text { Group F } \\
\text { (Text) } \\
\& \\
\text { Control group } \\
\text { (C \& D) }\end{array} \\
\text { d-value }\end{array}$} & \multirow[t]{2}{*}{$\begin{array}{c}\text { Group E } \\
\text { (Multimedia) } \\
\& \\
\text { Group F } \\
\text { (Text) } \\
\end{array}$} \\
\hline & & & & & \multirow{2}{*}{$\begin{array}{c}\begin{array}{c}\text { Mean Square } \\
\text { Error }\end{array} \\
677.8\end{array}$} & \multirow{2}{*}{$\begin{array}{c}\mathrm{p} \text {-value } \\
0.3941\end{array}$} & & & \\
\hline \multirow{2}{*}{$\underset{\stackrel{n}{*}}{\stackrel{n}{H}}$} & Knowledge & 49.8 & 55.8 & 50.7 & & & 0.2 & 0.0 & 0.2 \\
\hline & Application & 59.5 & 66.5 & 70.1 & 372.8 & 0.0832 & 0.4 & 0.5 & 0.2 \\
\hline \multirow{2}{*}{ 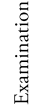 } & Knowledge & 70.4 & 73.2 & 70.9 & 847.8 & 0.8475 & 0.1 & 0.0 & 0.1 \\
\hline & Application & 57.8 & 62.3 & 47.7 & 524.1 & 0.0006 & 0.2 & 0.4 & 0.6 \\
\hline
\end{tabular}




\section{Geography analysis and results for the theme Natural Resources}

The analysis of Table 4 shows the adjusted mean scores, mean square errors, p-values and the effect sizes (d-values) of ANCOVA for Test 3 and the examination. The table refers to Knowledge and Application questions answered in the Geography theme Natural Resources, adjusted for the pre-test results.

In Table 4 the Knowledge outcome for the examination shows that the three groups performed reasonably the same, with the control group (E and $\mathrm{F}$ ) performing the best (93.3\%). The groups differed significantly statistically. The comparison between the control group (E and F) and the experimental group (group C) yielded a medium effect size (0.5), meaning that the control group was visibly better than group C.

The mean scores of the three groups for the Application outcome for the examination differed significantly statistically. Group D (Multimedia-DVD 2 ), who received moving and still graphics with audio and text as well as excerpts showing natural resources, performed the best (63.9\%).

The mean scores of the three groups for the Application outcome for the examination differed significantly statistically. Group D (Multimedia-DVD 2 ), who received moving and still graphics with audio and text as well as excerpts showing Natural Resources, performed the best (63.9\%). Table 4 shows a medium effect size of $\mathrm{d}=0.5$ between group $\mathrm{D}$ and the control group ( $\mathrm{E}$ and $\mathrm{F}$ ), and between group $\mathrm{D}$ and group $\mathrm{C}$, meaning that group $\mathrm{D}$ performed visibly better.

Table 4: Adjusted mean scores, mean square errors, p-values and effect sizes (d-values) of ANCOVA theme Natural Resources

\begin{tabular}{|c|c|c|c|c|c|c|c|c|c|}
\hline \multirow{2}{*}{\multicolumn{2}{|c|}{$\begin{array}{c}\text { Geography } \\
\text { Theme } \\
\text { Natural } \\
\text { Resources }\end{array}$}} & $\begin{array}{c}\text { Control } \\
\text { group } \\
(\mathrm{E} \& \mathrm{~F})\end{array}$ & $\begin{array}{c}\text { Group C } \\
\text { (Text) }\end{array}$ & $\begin{array}{c}\text { Group D } \\
\text { (Multimedia) }\end{array}$ & & & $\begin{array}{c}\text { Group C } \\
\text { (Text) } \\
\& \\
\text { Control group } \\
\text { (E \& F) }\end{array}$ & $\begin{array}{c}\text { Group D } \\
\text { (Multimedia) } \\
\& \\
\text { Control group } \\
\text { (E \& F) }\end{array}$ & $\begin{array}{c}\text { Group D } \\
\text { (Multimedia) } \\
\& \\
\text { Group C } \\
\text { (Text) }\end{array}$ \\
\hline & & \multicolumn{3}{|c|}{$\begin{array}{c}\text { Adjusted Mean } \\
\% \\
\end{array}$} & $\begin{array}{c}\text { Mean Square } \\
\text { Error }\end{array}$ & p-value & \multicolumn{3}{|c|}{ d-value } \\
\hline \multirow{2}{*}{ 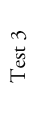 } & Knowledge & 70.1 & 65.8 & 66.1 & 331.8 & 0.2028 & 0.2 & 0.2 & 0.0 \\
\hline & Application & 82 & 78.1 & 79.3 & 590.4 & 0.5902 & 0.2 & 0.1 & 0.0 \\
\hline \multirow{2}{*}{ 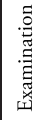 } & Knowledge & 93.3 & 84.2 & 88.3 & 286.1 & 0.0009 & 0.5 & 0.3 & 0.2 \\
\hline & Application & 52.3 & 53.2 & 63.9 & 493.4 & 0.0018 & 0.0 & 0.5 & 0.5 \\
\hline
\end{tabular}




\section{Geography analysis and results for the theme Sustainable Development}

The analysis of Table 5 shows the adjusted mean scores, mean square errors, p-values and the effect sizes (d-values) of ANCOVA for Test 4 and the examination. The table refers to Knowledge and Application questions answered in the Geography theme Sustainable Development, adjusted for the pre-test results.

The Knowledge outcome for the examination shows that the control group $(\mathrm{C}$ and $\mathrm{D})$ performed the best $(56.4 \%)$ and the analysed data shows that statistical significance was obtained. A visible effect size of $\mathrm{d}=0.4$ was obtained for the comparison between the control group (C and D) and group F. The same motivation given for the Knowledge outcome in the examination for the Natural Resources theme is applicable here.

The Application outcome for the examination shows that group E, who received DVD 1 with text and audio, performed the best (56.2\%). A statistical significant difference in the mean scores of the three groups for the Application outcomes in the examination is seen in Table 5. A visible effect size of $\mathrm{d}=0.4$ between group $\mathrm{F}$ (Multimedia) and group $\mathrm{E}$ (Text) shows that group E performed visibly better than group F in the Application outcomes in the examination.

Table 5: Adjusted mean scores, mean square errors, p-values and effect sizes (d-values) of ANCOVA for the theme Sustainable Development

\begin{tabular}{|c|c|c|c|c|c|c|c|c|c|}
\hline \multirow{2}{*}{\multicolumn{2}{|c|}{\begin{tabular}{|c|} 
\\
Geography \\
Theme \\
Sustainable \\
Development
\end{tabular}}} & $\begin{array}{l}\text { Control } \\
\text { group } \\
(C \& D)\end{array}$ & $\begin{array}{l}\text { Group E } \\
\text { (Text) }\end{array}$ & $\begin{array}{c}\text { Group F } \\
\text { (Multimedia) }\end{array}$ & \multirow{3}{*}{$\begin{array}{c}\begin{array}{c}\text { Mean Square } \\
\text { Error }\end{array} \\
577.5\end{array}$} & \multirow{3}{*}{$\begin{array}{c}\text { p-value } \\
0.0578\end{array}$} & $\begin{array}{c}\text { Group E } \\
\text { (Text) } \\
\& \\
\text { Control group } \\
\text { (C \& D) } \\
\end{array}$ & $\begin{array}{c}\text { Group F } \\
\text { (Multimedia) } \\
\& \\
\text { Control group } \\
\text { (C \& D) } \\
\end{array}$ & $\begin{array}{c}\text { Group F } \\
\text { (Multimedia) } \\
\& \\
\text { Group E } \\
\text { (Text) }\end{array}$ \\
\hline & & \multicolumn{3}{|c|}{$\begin{array}{c}\text { Adjusted Mean } \\
\%\end{array}$} & & & \multicolumn{3}{|c|}{ d-value } \\
\hline \multirow{2}{*}{ 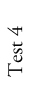 } & Knowledge & 71.4 & 78.4 & 67.1 & & & 0.3 & 0.2 & 0.5 \\
\hline & Application & 83 & 86.9 & 84.7 & 541.9 & 0.6176 & 0.2 & 0.1 & 0.1 \\
\hline \multirow{2}{*}{ 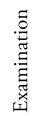 } & Knowledge & 56.4 & 49.7 & 46.9 & 508.1 & 0.0291 & 0.3 & 0.4 & 0.1 \\
\hline & Application & 53 & 56.2 & 47.1 & 479 & 0.0496 & 0.1 & 0.3 & 0.4 \\
\hline
\end{tabular}

\section{Discussion of results}

A possible reason why groups $\mathrm{E}$ and $\mathrm{F}$ performed better (Tables $2 \& 3$ ) in the analysis and results for the theme Sources in History is that it was the first time that the students were exposed to ICT by means of multimedia. Unaccustomed, they had to apply their knowledge to answer questions after 
using a multimedia DVD. The possibility exists that the multimedia on DVD 2 contained complex verbal and pictorial representations, causing the students to experience a lack of guidance compared to the control group, since it is difficult to distinguish the difference between primary and secondary sources (Van Eeden, 1999:211). The possibility also exists that because the concept was too difficult to understand, the combination of the media did not have the expected effect on the outcome (ChanLin, 1998). Cognitive overload may also have contributed to poor analysis and connection of information during the processing stage (Woolfolk, 1998:262; Moreno, 2004:102; Gilakjani, 2012:58), since less relevant information may have formed part of the multimedia design on the DVDs. The presence of the lecturer during the contact session meant that it was possible to assess students' learning before the end of the lecture. Students were therefore forced to apply their knowledge to the summative questions posed. This was not the case with the students who received the DVDs, since their discourse took place during the following scheduled contact session.

A possible reason for the results for the theme Democracy in the History analysis is that the visuals used on DVD 2 (multimedia) provided a clear schematic outlay of the important components of a democratic system that had to be mastered in the outcomes. The concepts were easily understood with the aid of various multimedia, including contemporary, relevant and applicable excerpts from the news that were most likely watched over and over. In support of this finding, Lee (2002:512-513) states that "digital historical resources made university students return to the same documents time and again. History learners also rated visual media as most useful since it helps to visualise events, and students are more accustomed to technological experiences in the web-based world of our time" (Lee, 2002:512-513). This may explain why Application questions showed higher means for group $\mathrm{E}$ (multimedia DVD) when compared to the other two groups. These outcomes confirm that humans possess separate channels for processing visual and auditory information. Students therefore learn more deeply from multimedia using text and picture explanations than from a verbal explanation like DVD 1 containing text with audio (De Sousa et al., 2008; Mayer, 2001:47; Mayer, 2003: 127). This shows that a strong relationship exists between multimedia presentations and students learning for the theme Sources.

Natural Resources' knowledge outcomes in the results and analysis in Geography that were answered in the examination produced the best adjusted 
mean scores by the group receiving a traditional contact lecture. In general, the experimental groups using DVD 1 and 2 show that good scores can also be achieved and teaching styles can be changed when integrating multimedia into teaching and learning. However, this result was not what was expected beforehand. Nonetheless, this non-effect is also a finding. This could mean that the students have not yet learned to make the shift to learning with multimedia and that their style of learning has not changed. Nugent's (1982:164) research reminds us that a subject, with its unique characteristics, influences the success of learning via pictures or audio presentations.

The higher means yielded by group D (Multimedia-DVD 2) may be due to student learning being enhanced by visual material on a DVD containing moving graphics with explanations and many examples of the types of Natural Resources and their processes in the form of tangible picture illustrations.

The data analysis revealed that when assessing Application outcomes during an examination, a DVD containing text with audio will lead to the best results if used for teaching and learning the Geography theme of Sustainable Development. Text is therefore more advantageous when the material becomes more complex, as Nugent $(1982: 164)$ found in his research. For this theme the complex concept does not require visual aids. It is the use of literature that helps build up fundamental knowledge and understanding for Application outcomes (De Sousa, 2008:96). The noun phrase, Sustainable Development, consists of two words functioning as a noun. It requires one to understand the twofold concept. The students might have struggled more to understand this last theme in the Geography section, since they had to comprehend that the need for economic development must be accompanied by minimal harm and pollution to the environment so that future generations are not deprived of the earth's riches.

Of great importance is the fact that research by ChanLin (1998:1) found that if a concept such as Sustainable Development "is too difficult to understand then the presentation will be unsuccessful, no matter what media is used". Student achievement by the group that received DVD 1 containing text was superior since:

- the lecturer presented the words in a personalised conversational style rather than a detailed descriptive style (Mayer, 2002:67; Mayer, 2001:44);

- group E may be theory or verbal learners who "learn better with text" and found that the spoken explanations on DVD 1 were more helpful when answering the Knowledge questions. It may also be that the students of group $\mathrm{E}$ were used to 
learning in an environment with text and audio ( $c f$. De Sousa et al., 2008; Reay, 1997:83; Guimaraes, Chambel \& Bidarra, 2000), and

- "high prior-knowledge may lead to mental images being produced while reading a verbal text" (cf. De Sousa et al., 2008:56-59; Mayer et al., 2000:4).

\section{Conclusion}

It has been established that the nature of the theme and the outcome assessed are factors that play a role in determining what the multimedia structure and format should look like on DVD for SS teaching and learning at a tertiary institution. The use of multimedia resources like visual sources and documentary excerpts did not have the expected effect on student learning throughout the four themes when assessing knowledge and application outcomes. However, their inclusion was beneficial and not detrimental to student learning. In History teaching, a DVD can be integrated successfully into the teaching and learning of Sources and Democracy themes if it contains text, audio, still and moving graphics, schematic representations, and documentary excerpts. The DVD structure and format for Geography teaching and learning that can benefit student learning within SS is dependent on the nature of the theme in Geography.

In both disciplines one can deduce from the best performances by the groups using DVD 1 and DVD 2 that constructive learning as active, outcomeoriented and self-regulated learning with the aid of ICT and multimedia can result in good achievement by students. The study shows that by using multimedia, not only are different teaching and learning styles used, but the approach to learning is also different and it helps learners to construct their own knowledge. Current teaching strategies have not been successful in promoting problem-solving skills, curiosity, and critical and logical thinking. ICT and its innovative possibilities cater for enriched approaches for meaningful learning (Shah \& Khan, 2015:349). The use of the multimedia could be useful in History and Geography teaching to make the learning experience more meaningful in SS.

\section{References}

Bartlett, RM \& Strough, J 2003. Multimedia versus traditional course instruction in introductory social psychology. Teaching of Psychology, 30:335-338. 
Bernhard, J 2007. Thinking and learning through technology mediating tools and insights from philosophy of technology applied to science and engineering education. In: N Sanit (ed.). The Pantaneto Forum. Available at http://www.pantaneto. co.uk/issue27/front27.htm. Accessed on 22 August 2008.

Bridges.org. 2002. Spanning the Digital Divide. Understanding and tackling the issues. Durbanville: Bridges.org.

ChanLin, L 1998. Animation to teach students of different knowledge levels. Journal of Instructional Psychology, 25(3):1-9.

Coetzee-Van Rooy, AS 2003. Concept moderator's report. In: Institutional course for newlyappointed lecturers. Potchefstroom: North-West University.

Crosby, ME \& Stelovsky, J 1995. From multimedia instruction to multimedia evaluation. Journal of Educational Multimedia and Hypermedia, 4:147-162.

DoE see South Africa. Department of Education.

DBE see South Africa. Department of Basic Education.

De Sousa, LO 2008. The integration of Digital Video Discs (DVDs) and multimedia in the Learning Area Social Sciences. Unpublished MEd dissertation. Potchefstroom: North-West University.

De Sousa, LO \& Van Eeden, ES 2009. Clear-cut to high-tech: History teaching and learning support material (TLSM) drawing on information and communication technology (ICT). Yesterday \& Today, 4:17-40.

Ekinci, D, Karakoç, E, Hut, D \& Avc1, HE 2009. Using Multimedia Technologies as a current trends on Social Sciences education. International Sustainable Symposium on Development Proceedings, Additional volume: 93-106.

Elen, J \& Louw, LP 2006. The instructional functionality of multiple adjunct aids. e-Journal of Instructional Science and Technology, 9(2). Available at http://www.usq.edu. au/electpub/e-jist/docs/vol9_no2/default/htm. Accessed on 22 August 2008.

Ellis, SM \& Steyn, HS 2003. Practical significance (effect sizes) versus or in combination with statistical significance (p-values). Management Dynamics, 12(4):51-53.

Evoh, CJ 2007. Collaborative partnerships and the transformation of Secondary education through ICTs in South Africa. Educational Media International, 44(2):81-98.

Gardner, H 1999. Intelligence reframed. Multiple intelligences for the 21st century. New York, NY: Basic Books. 
Gerster, R \& Zimmerman, S 2003. Information and communication technologies and poverty reduction in Sub-Saharan Africa. Richterswil: Gester Consulting.

Gilakjani, AP 2012. The significant role of multimedia in motivating EFL learners' interest in English Language learning. International Journal of Modern Education and Computer Science, 4:57-66.

Goktas, Y, Yildirim, S \& Yildirim, Z 2009. Main barriers and possible enablers of ICTs integration into pre-service teacher education programs. Educational Technology \& Society, 12(1):193-204.

Golightly, A, Nieuwoudt, H \& Richter, BW 2005. Kriteria en strategieë vir die optimering van kontaktyd in die bereiking van leeruitkomste in die Geografie-opleiding van onderwysstudente. Ongepubliseerde PhD-tesis. Potchefstroom: NoordwesUniversiteit.

Guimaraes, N, Chambel, T \& Bidarra, J 2000. From cognitive maps to hyper video: Supporting flexible and rich learner-centred environments. Interactive Multimedia Electronic Journal of Computer-Enhanced Learning, 2(2). Available at http://imej.wfu.edu/articles/2000/2/03/\#top. Accessed on 8 March 2007.

Howie, SJ, Muller, A \& Paterson, A 2005. Information and communication technologies in South African secondary schools. Cape Town: HSRC Press.

Issa, RRA, Cox, RF, \& Killingsworth, CF 1999. Impact of multimedia-based instruction on learning and retention. Journal of Computing in Civil Engineering, 13(4):281-290.

Jacobsen, M, Clifford, P \& Friesen, S 2002. Preparing teachers for technology integration: Creating a culture of inquiry in the context of use. Contemporary Issues in Technology and Teaching, 2(3):363-388.

Leedy, PD \& Ormrod, JE 2005. Practical research: Planning and design. Upper Saddle River, NJ: Merrill Prentice Hall.

Lee, JK 2002. Digital history in the History/Social Sciences classroom. The History Teacher, 35(4):503-517.

Lee, Y, \& Keckley, K 2006. Effects of a teacher-made multimedia program on teaching driver education. Teaching exceptional children plus, 2(5) Article 5. Available at http:// escholarship.bc.edu/education/tecplus/vol2/iss5/art5. Accessed on 4 November 2016.

Jarosievitz, B 2009. ICT use in science Education. In: AM Vilas, AS Martín, JAM González. Research, reflections and innovations in integrating ICT in education: Proceedings of the fifth international conference on multimedia and ICT in education, 1:382-386. 
Jarosievitz, B 2011. ICT, Multimedia used in the national and international educational projects. Informatika, 38: 22.

Jarosievitz, B 2015. The impact of ICT and multimedia used to flip the classroom (Physics lectures) via smart phones and tablets, pp. 1-6. Conference paper September. Available at http://www.sukjaro.eu/JBea/pdf/MPTL20_Proceedings_cikk_jb.pdf. Accessed on 4 November 2016.

Malik, S \& Agarwal, A 2012. Use of multimedia as a new educational technology tool - A study. International Journal of Information and Education Technology, 2(5):468-471.

Mayer, RE 2001. Multimedia learning. Cambridge: Cambridge University Press.

Mayer, RE 2002. Cognitive theory and the design of multimedia instruction: An example of the two-way street between cognition and instruction. New Directions for Teaching and Learning, 89:55-71.

Mayer, RE 2003. The promise of multimedia learning: using the same instructional design methods across different media. Learning and Instruction, 13:125-139.

Mayer, RE \& Moreno, R 2000. A cognitive theory of multimedia learning: Implications for design principles. Available at http://www.unm.edu/ -moreno/PDFS/chi.pdf. Accessed on 1 March 2007.

Mayer, RE \& Moreno, R 2003. Nine ways to reduce cognitive load in multimedia learning. Education Psychologist, 38(1):43-52.

McKendrick, JH \& Bowden, A 1999. Something for everyone? An evaluation of the use of audio-visual resources in geographical learning in the UK. Journal of Geography in Higher Education, 23(1):9-19.

Moreno, R 2004. Decreasing cognitive load for novice students: Effects of explanatory versus corrective feedback in discovery-based multimedia. Instructional Science, 32:99-113.

Munro, R 2000. Exploring and explaining the past: ICT and History. Education Media International, 37(4):251-256.

National Council for Accreditation of Teacher Education. 1997. Technology and the new professional teacher. Washington, DC: National Council for Accreditation of Teacher Education. Available at http://www.ncate.org/Home/tabid/680/ Default.aspx. Accessed on 2 August 2016.

Niess, ML 2005. Preparing teachers to teach science and mathematics with technology: Developing a technology pedagogical content knowledge. Teaching and Teacher Education, 21:509-523. 
Nugent, GC 1982. Pictures, audio, and print: symbolic representation and effect on learning. Educational Communication and Technology, 30(3):163-174.

Otts, DA, Williams, A, Dawson, CW \& Alley, VRM 1999. Getting started with multimedia in the classroom and tutorial lab. Available at https://archive.org/stream/ERIC_ ED436111/ERIC_ED436111_djvu.txt. Accessed on 8 November 2016.

Persichitte, KA, Tharp, DD \& Caffarella, EP 1998. Pre-service teacher preparation and interactive information technologies. In: Proceedings of selected research and development presentations at the National Convention of the Association for Educational Communications and Technology (AECT), 18-22 February.

Peterson, G 1994. Geography and technology in the classroom. NASSP Bulletin, 78(564):25-29.

Reay, DG 1997. Understanding how people learn. East Brunswick, NJ: Nicholas Publishing.

Rodríguez, P, Nussbaum, M, López, X \& Sepúlveda, M 2010. A monitoring and evaluation scheme for an ICT-supported education program in schools. Educational Technology \& Society, 13(2):166-179.

Schnotz, W \& Lowe, R 2003. External and internal representations in multimedia learning. Learning and Instruction, 13:117-123.

Shah, I \& Khan, M 2015. Impact of multimedia-aided teaching on students' academic achievement and attitude at elementary level. US-China Education Review A, 5(5):349-360.

South Africa. Department of Basic Education. 2015. Action plan to 2019: Towards the realisation of schooling 2030: Taking forward South Africa's National Development Plan 2030. Pretoria: Government Printer.

South Africa. Department of Basic Education. 2011a. National Curriculum Statement (NCS). Curriculum and assessment policy statement. Social Sciences, Intermediate phase grades 4-6. Pretoria: Government Printing Works.

South Africa. Department of Basic Education. 2011b. National Curriculum Statement (NCS). Curriculum and assessment policy statement. Social Sciences, senior phase grades 7-9. Pretoria: Government Printer.

South Africa. Department of Education. 2003. Draft White Paper on e-Education transforming learning and teaching through Information and Communication Technologies (ICTs). Pretoria: Government Printer.

Srivastava, TK, Waghmare, LS, Jagzape, AT, Rawekar AT, Quazi, NZ \& Mishra" VP 2014. Role of Information Communication Technology in Higher Education: Learners perspective in rural medical schools. Journal of Clinical and Diagnostic Research, 8(6):XC01-XC06. 
Tufte, ER 1990. The visual display of quantitative information. Princeton, NJ: Princeton University.

United Nations Economic Commission for Africa. 2002. ICT Focus group. Available at http://www.uneca.org/sites/default/files/uploaded-documents/ADF/ADF3/ ict_statement.pdf. Accessed on 26 August 2016.

Van Eeden, ES 1999. Didactical guidelines for teaching History in a changing South Africa. Potchefstroom: Keurkopie.

Vincent, A \& Shepherd, J 1998. Experiences in teaching Middle East politics via internetbased role-play simulations. Journal of Interactive Media in Education, 98(11). Available at http://www-jime.open.ac.uk/articles/10.5334/1998-11/. Accessed on 26 August 2016.

Webster's College Dictionary.1991. New York, NY: Random House.

West, RL \& Crook, TH 1992. Video training of imaginary for mature adults. Journal of Applied Cognitive Psychology, 6(4):308-320.

Weiner, RG 1995. History: Teaching and methods. ERIC Document reproduction service No. ED 387 402. Accessed on 05 August 2005.

Woolfolk, AE 1998. Educational psychology. Boston, Mass.: Allyn \& Bacon.

Zeng, B, Warschauer, M, Hsi Lin, M \& Chang, C 2016. Learning in one-to-one laptop environments: A meta-analysis and research synthesis. Review of Educational Research, 20(10):1-33. 